\title{
Chapter 51
}

\section{A Scoring System for Intravesical Therapy and NMIBC}

An accurate prediction of progression is critically important in the management of non-muscle-invasive bladder cancer $\sim($ Fujii 2018). At present, three risk models are widely known for prediction of the risk of tumor recurrence and progression of non-muscle-invasive bladder cancer: the European Organization for Research and Treatment of Cancer, Club Urológico Español de Tratamiento Oncológico, and new European Organization for Research and Treatment of Cancer models (2018).

Ofude et al. (2015) investigated whether the European Organization for Research and Treatment of Cancer (EORTC) scoring system is appropriate for selection of adjuvant intravesical therapies for non-muscle-invasive bladder cancer (NMIBC) (Ofude et al. 2015). Tumor number, size, and grade were significant predictors of time to recurrence. In groups with intermediate recurrence the recurrence prevention effects in those with an EORTC score of $\geq 5$ were significantly greater with intravesical Bacillus Calmette-Guérin therapy than with weekly intravesical chemotherapy (Ofude et al. 2015).

\section{References}

Fujii Y. Prediction models for progression of non-muscle-invasive bladder cancer: a review. Int J Urol. 2018;25(3):212-8.

Ofude M, Kitagawa Y, Yaegashi H, Izumi K, Ueno S, Kadono Y, Konaka H, Mizokami A, Namiki M. Selection of adjuvant intravesical therapies using the European organization for research and treatment of cancer scoring system in patients at intermediate risk of non-muscle-invasive bladder cancer. J Cancer Res Clin Oncol. 2015;141(1):161-8. 